\title{
A questão da técnica no pensamento de Heidegger
}

\section{The question concerning technology in Heidegger's thought}

DOI:10.12957/ek.2019.42714

Dr. Felipe Shimabukuro felipe.shimabukuro@malix.univ-paris1.fr Universidade de Paris 1 - Panthéon-Sorbonne

O objetivo deste artigo é propor uma leitura sobre a questão da técnica no pensamento de Heidegger. A hipótese que anima tal leitura é a seguinte: a técnica moderna é a metafísica do capitalismo, o que significa que o capitalismo não é unicamente um modo de produção da vida material, mas também uma metafísica. Para tornar o sentido dessa hipótese inteligível, será necessário explicar, num primeiro momento, a relação entre a questão da técnica e as noções de história do ser e de metafísica como onto-teologia, para que, num segundo momento, seja possível determinar a essência da técnica a partir de uma leitura cruzada Heidegger-Marx.

PALAVRAS-CHAVE Heidegger. Marx. Técnica. Metafísica. Capitalismo

This paper aims to propose an interpretation of the question concerning technology in Heidegger's thought. The hypothesis which animates this interpretation is the following one: the modern technology is the capitalism's metaphysics, which means that the capitalism is not only a mode of production of material life, but also a metaphysics. To make the sense of this hypothesis intelligible, we will need to explain firstly the relationship between the question concerning technology and the notions of history of being and metaphysics as onto-theology; we will determine secondly the technology's essence through a cross-reading between Heidegger and Marx.

KEYWORDS Heidegger. Marx. Technology. Metaphysics. Capitalism 


\section{Introdução}

De acordo com o método heideggeriano de leitura, o que há de mais importante, rico e essencial no pensamento de todo grande filósofo, não é tanto aquilo que ele disse e pensou explicitamente em seus textos, mas justamente aquilo que ele não disse explicitamente. Daí a noção heideggeriana de não-dito (das Ungesagte), cujo sentido fundamental é: no pensamento de todo grande filósofo sempre há algo que ele pensou sem saber, sempre há algo da ordem do impensado (das Ungedachte), ou seja, que o filósofo pensou sem ter reconhecido como sendo o seu próprio pensamento. $\mathrm{Na}$ obra de Heidegger, o estatuto do não-dito e impensado aparece em sua forma mais bem acabada nessas duas passagens: 1) “A 'doutrina' de um pensador é o não-dito (das Ungesagte) em seu dizer" (Heidegger, 2004, p. 203). 2) "Quanto maior é a obra de pensamento de um pensador (...), mais rico é o impensado (das Ungedachte) nessa obra de pensamento" (Heidegger, 1997, p. 105)1.

As noções de não-dito e impensado se articulam, por sua vez, com o conceito de verdade como desvelamento (Unverborgenheit) ou $\dot{\alpha} \lambda \hat{\eta} \theta \varepsilon \iota \alpha$, que possui o estatuto de dimensão originária e não metafísica da verdade em relação à verdade como adequação (Übereinstimmung, Richtigkeit). Tal articulação significa que a verdade da leitura de um texto filosófico não consiste tanto na adequação entre leitura proposta e intenção do filósofo, mas acima de tudo no desvelamento do não-dito e impensado em seu pensamento. Nesse sentido, Heidegger compreende os textos da história da filosofia a partir de duas camadas: o explicitamente dito e o não-dito a ser desvelado, o explicitamente pensado e o impensado a ser desvelado. De um ponto de vista heideggeriano, a verdadeira leitura filosófica é, portanto, aquela que, ao invés de tentar reproduzir fielmente aquilo que um pensador quis dizer em seus textos, procura antes de tudo desvelar o não-dito e impensado de seu pensamento.

Em seus textos sobre a técnica moderna, Heidegger a tematiza enquanto última época da história da metafísica concebida como história do ser. Em nenhuma passagem destes textos ele diz explicitamente que sua meditação sobre a técnica é uma forma de apreender a metafísica subjacente ao capitalismo. A hipótese de leitura que propomos no presente artigo é justamente que a questão do capitalismo é o não-dito e impensado dos textos heideggerianos sobre a

1 A questão do não-dito (das Ungesagte) e do impensado (das Ungedachte) nunca foi objeto de uma reflexão sistemática por parte de Heidegger. Essa questão está dispersa em diversas passagens da Gesamte Ausgabe. Cf. GA 3, p. 249, GA 8, p. 57, 82-83, GA 9, p. 203, GA 10, p. 57, 105, GA 15, p. 89, 113, GA 19, p. 46, 77, 78, GA 53, p. 133, GA 55, p. 180, GA 79, p. 132, 504, GA 82, p. 486, GA 94, p. 258, GA 97, p. 244, 504. 
técnica. Para explicitar o sentido dessa hipótese, procederemos em dois grandes blocos. Num primeiro momento, trata-se de tecer algumas considerações sobre a noção de história do ser e sua relação com o conceito de metafísica como onto-teologia. Num segundo momento, articularemos o pensamento de Heidegger sobre a técnica com alguns conceitos de Marx.

\section{A história do Ocidente enquanto história do ser}

Embora a primeira ocorrência da expressão Geschichte des Seins (história do $\mathrm{ser}^{2}$ ) se encontre em Introdução à metafísica ${ }^{3}$ - curso ministrado por Heidegger em 1935 na Universidade de Friburgo e publicado somente em 1953 -, a noção de história do ser só será objeto de um primeiro desenvolvimento mais sistemático entre 1936 e 1939, nos Beiträge zur Philosophie (1936-1938) e principalmente no curso sobre Nietzsche em 1939.

A qual problema filosófico responde a noção heideggeriana de história do ser? Trata-se de um problema moderno que se tornou conhecido através de uma expressão inventada por Voltaire em 1765: philosophie de l'histoire. Isso significa que Heidegger introduz a noção de história do ser a fim de propor sua versão de uma filosofia da história, problema que ocupou diversos autores da tradição do pensamento alemão. Tal problema diz respeito à articulação entre duas concepções da história: a história empírica dos fatos feita pelos historiadores e a história do sentido do processo histórico feita pelos filósofos. Esse problema anima obras como Mais uma filosofia da história para a formação da humanidade (1774) e Ideias para a filosofia da história da humanidade (1784-1791) de Herder, Ideia de uma história universal de um ponto de vista cosmopolita (1784) de Kant, a Fenomenologia do espírito (1807) e as Conferências sobre a filosofia da história (1837) de Hegel. A noção heideggeriana de história do ser se inscreve nessa linhagem da filosofia alemã e procura dar conta da articulação entre história empírica dos fatos, que Heidegger designa através dos termos Historie e historisch, e história filosófica do sentido do processo histórico, designada através dos termos Geschichte e geschichtlich.

Em que consiste a especificidade da filosofia heideggeriana da história? Diferentemente de Hegel e Marx, por exemplo, Heidegger concebe a história do

2 Heidegger escreve essa expressão de quatro modos distintos ao longo de sua obra: Geschichte des Seins, Geschichte des Seyns, Seinsgeschichte e Seynsgeschichte.

3 Ver Einführung in die Metaphysik, GA 40, Frankfurt: Klostermann, 1983, p. 99 
Ocidente como a história do ser e não do espírito ou dos modos de produção da vida material. Ao invés de propor uma concepção da história e suas diferentes épocas enquanto diferentes figuras do espírito ou dos modos de produção, Heidegger faz uma leitura do processo histórico a partir da relação entre ser e homem, entre homem e ser. O que isso significa? Isso significa que cada época da história do Ocidente se define fundamentalmente por um regime de manifestação ou desvelamento do ser dos entes na totalidade. Na terminologia de Heidegger, o ser se destina aos homens em cada época da história através de um determinado regime de presença da totalidade do ente:

aquilo que está presente (das Anwesende) pode interpelar o homem de acordo com diferentes modos de presença (Anwesenheit). Estes diferentes modos determinam as épocas da história ocidental do ser (Epochen der abendländischen Seynsgeschichte) (Heidegger, 2005, p. 39).

Para Heidegger, cada época da história do Ocidente se define por um modo através do qual o ser se destina aos homens. Nesse sentido, o filósofo utiliza "o termo Seinsgeschick (destinação/destino do ser) para designar as épocas do ser (Epochen des Seins)" (Heidegger, 1986, p. 339), de modo que "as diferentes épocas da história do ser (Geschichte des Seins) - as diferentes e sucessivas suspensões do ser em sua destinação (Geschick) - são as épocas dos diferentes modos através dos quais a presença (Anwesenheit) se destina (zuschickt) ao homem ocidental" (Heidegger, 1986, p. 367). A história do Ocidente é, portanto, a história dos modos como o ser enquanto presença se destina aos homens, e dentre eles os filósofos são aqueles que, aclamados pela voz do ser, elevam seu modo epocal de destinação à linguagem. De que modo os filósofos elevam o ser a linguagem? Para responder esta questão, é preciso compreender como a noção de história do ser se articula com a noção de metafísica como onto-teologia.

\section{A metafísica como onto-teologia e as diferentes épocas da história do ser}

A primeira ocorrência das expressões Ontotheologie e Onto-theo-logie se encontra no curso sobre a Fenomenologia do espírito de Hegel em 1930- 
1931 na Universidade de Friburgo ${ }^{4}$. No interior da Gesamte Ausgabe, os dois pontos culminantes da elaboração e desenvolvimento dessa noção estão em Introdução à "O que é metafísica?" (1949) e A constituição onto-teo-lógica da metafísica (1956/57).

A noção de onto-teologia torna-se central no pensamento de Heidegger ao longo dos anos 1930, período em que ela passa a incarnar a definição mesma daquilo que o filósofo entende por metafísica. Em que consiste o conceito heideggeriano de metafísica como onto-teologia? Através dessa noção, Heidegger cria um conceito absolutamente singular e único de metafísica. Em primeiro lugar, trata-se de desvencilhar-se de três acepções correntes do termo metafísica: enquanto setor ou disciplina filosófica como a estética, a ética, a lógica, a filosofia política, etc., enquanto disciplina e campo de pesquisa acadêmica e enquanto sistema filosófico ou doutrina de um pensador: "Pensada de modo rigoroso, a metafisica nunca é entendida aqui como parte de uma doutrina (Lehrstück), como 'disciplina' filosófica (philosophische Disziplin), como forma do conhecimento (Erkenntnisform) e coisas do gênero, mas como o destino do próprio ente na totalidade rumo ao ente enquanto tal' (Heidegger, 1997b, p. 382) ${ }^{5}$. Em outros termos, a metafisica enquanto onto-teologia é a história mesma do Ocidente enquanto história do ser. Vejamos melhor o que isso quer dizer.

O conceito heideggeriano de onto-teologia nasce de uma apropriação e

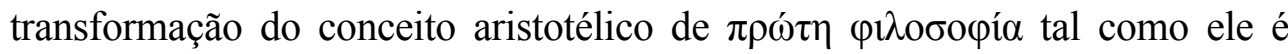
formulado no início do livro IV da Metafísica:

Existe uma ciência ( $\left.\dot{\varepsilon} \pi \_\tau \eta \dot{\mu \eta}\right)$ que tem como objeto o ente enquanto ente ( $\tau$ ò ôv $\tilde{\tilde{n}}$ ôv) e os atributos que lhe são essencialmente inerentes. Ela não se confunde com nenhuma das ciências ditas particulares, visto que nenhuma delas considera o ente enquanto ente em geral, mas fazendo um recorte de certa região do ente, é somente desta região que elas estudam o atributo: esse é o caso da matemática. E como procuramos os princípios

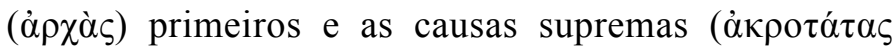

4 Cf. Hegels Phänomenologie des Geistes, GA 32, Frankfurt: Klostermann, 1997, p. 140, $141,142,143$.

5 Ainda sobre o mesmo assunto: 1) "A metafísica não se deixa abandonar como uma opinião (Ansicht). Não se pode de modo algum deixá-la para trás como uma doutrina (Lehre) em que não acreditamos e que não defendemos mais" (Heidegger, 2000a, p. 69). 2) "Pois essa 'metafísica' [de Nietzsche], como toda metafísica, não somente não é um sistema privado (Privatsystem), mas de modo algum um 'sistema' (System) no sentido de uma formação de pensamento depositada em livros. A metafísica é a verdade sobre o ente na totalidade, no interior da qual a verdade de uma respectiva época tem que se manter de tal e tal modo" (Heidegger, 2004b, p. 50). 


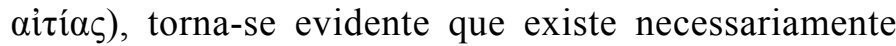
alguma realidade à qual tais princípios e causas são inerentes em virtude de sua própria natureza (...) Daí porque nós também devemos apreender as cau-

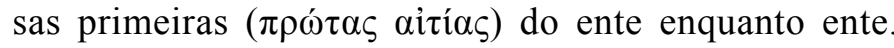
(Aristóteles, 1831, IV , 1, 1003 a 21-32)

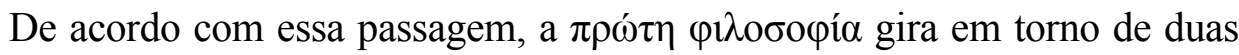

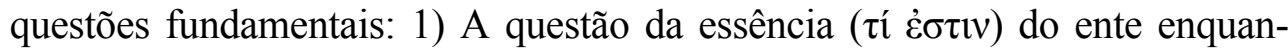

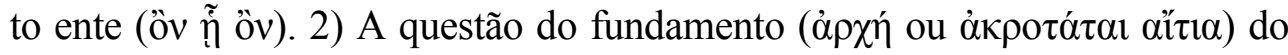
ente enquanto ente. Ora, são exatamente essas duas questões que permitirão a Heidegger conceber a essência da metafísica a partir de dois eixos:

1) A ontologia e sua questão fundamental: o que é o ente? ( $\tau$ í $\tau$ ò őv;). Nesse contexto, não se trata de nenhum ente particular como o homem, o amor, a vida, a natureza, a justiça, etc. Essa questão visa o ente enquanto ente, o ente na totalidade, isto é, aquilo que faz de todo e qualquer ente um ente, aquilo que é comum a todos os entes, definindo-os enquanto tais. Heidegger explica, assim, que a questão "o que é o ente?" visa "a essência universal do ente (allgemeine Wesen des Seienden): aquilo que faz do ente em geral um ente, independentemente do fato se esse ente é um animal ou uma planta, um homem, um astro, um triângulo, uma cadeira, um número ou um Deus; o ente independentemente deste ou daquele ente, mas exclusivamente em consideração do fato de que se trata do ente em geral. A questão do ente enquanto tal, ôv $\tilde{\tilde{n}}$ ő $v$; aquilo que faz do ente um ente: o ser (das Sein)" (Heidegger, 1997a, p. 25). Em suma, o eixo ontológico da metafísica diz respeito à questão da essência ( $\tau$ í $\dot{\sigma} \sigma \tau \imath$ ) ou ser do ente na totalidade.

2) A teologia e sua questão fundamental: por que o ente é o que é? Trata-se aqui da questão sobre o fundamento ou razão de ser (Grund) do ente na totalidade, questão que tem como objeto aqui-

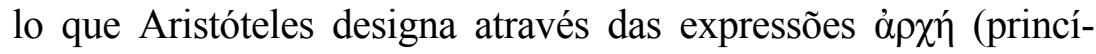

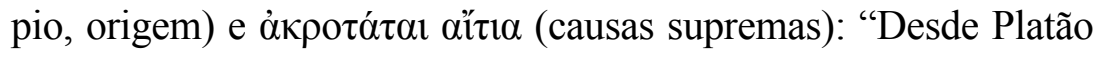

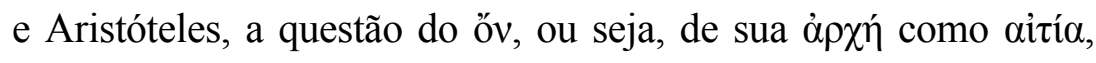

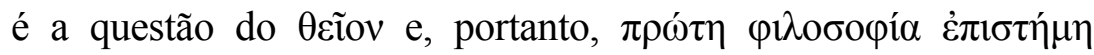

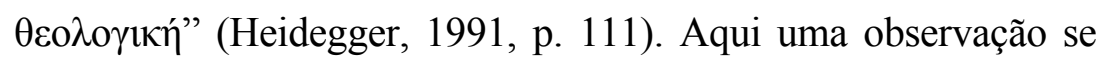


faz necessária: o uso heideggeriano dos termos Theologie e theologisch possui um sentido muito mais abrangente que em seu uso restrito à teologia cristã: a teologia é concebida por Heidegger a partir do horizonte metafísico da busca pelo fundamento último do ente na totalidade enquanto resposta filosófica que visa satisfazer as exigências do princípio de razão suficiente:

quando falamos aqui de 'teológico' (theologische) e de 'teologia' (Theologie), é preciso lembrar que a palavra e o conceito de 'teologia' não foram desenvolvidos pela primeira vez no âmbito e a serviço do sistema de fé da Igreja, mas no interior da filosofia (innerhalb der Philosophie). A palavra $\theta \varepsilon 0 \lambda$ o $\gamma i ́ \alpha$ nos é atestada relativamente

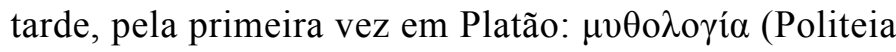
379a); essa palavra não está de modo algum presente no Novo Testamento. Toda filosofia enquanto metafísica é teologia no sentido originário e essencial da apreensão

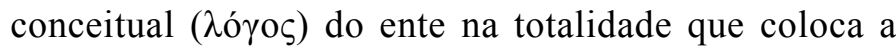
questão do fundamento (Grunde) (ou seja da causa [Ur-sache]) do ser, fundamento (Grund) cujo nome é $\theta \varepsilon o ́ s$, Deus. (Heidegger, 1988, p. 87)

Ainda sobre o uso particular e alargado que Heidegger faz do termo teologia:

A metafísica é em sua essência ontoteológica (ontotheologisch). Isso não vale apenas para a metafísica de Platão e Aristóteles, nem mesmo exclusivamente para a metafísica cristã. De Descartes a Nietzsche, a metafísica moderna também é uma ontoteologia (Ontotheologie). A justificação e evidência do princípio da certeza de si do ego cogito têm seu fundamento na idea innata substantiae infinitae, ou seja, Dei. Toda mônada percebe o universum numa perspectiva determinada e com isso a mônada central Deus. Segundo Kant, toda razão humana enquanto relação fundamental de sua essência com o ente é determinada inteiramente pelos postulados da razão prática, postulados em que a existência do bem supremo é posta como incondicionada. E, segundo 
Nietzsche, o ser como 'vontade de potência' só é possível tendo como fundamento $o$ incondicionado que ele só poderá enunciar como 'eterno retorno do mesmo'. (Heidegger, 1993, p. 81).

Em suma, a metafísica como onto-teologia representa o ente enquanto ente

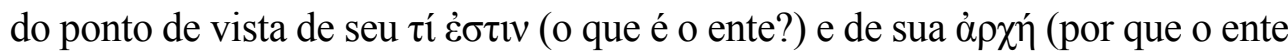
é o que é?):

Teo-logia significa aqui o questionamento sobre o ente na totalidade. A questão do ente na totalidade - a questão teológica - não pode ser colocada independentemente da questão do ente enquanto tal, da essência do ser em geral. Essa é a questão do ôv î̃ ôv, a 'ontologia'. O questionamento filosófico é sempre e em si mesmo duplo: onto-lógico e teo-lógico num sentido bastante amplo. Filosofia é ontoteologia (Ontotheologie)" (Heidegger, 1988, p. 88)

Se, por um lado, a noção heideggeriana de onto-teologia nasce de uma apro-

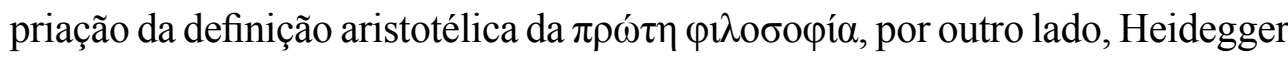
não se limita a reproduzi-la tal como ela se encontra em Aristotéles, visto que ele opera ao mesmo tempo uma transformação dessa noção. Tal transformação consiste exatamente na articulação entre metafísica como onto-teologia e história do Ocidente, ou seja, é o conceito de história do ser que confere à metafísica um significado e alcance muito mais amplos que em Aristóteles: a história da metafísica como onto-teologia ou história do ser é a própria história do Ocidente, tese propriamente heideggeriana e não aristotélica.

Agora dispomos de todos os elementos que nos permitem responder uma questão formulada anteriormente: de que modo os filósofos elevam o ser à linguagem? Os filósofos elevam o ser à linguagem através de uma resposta histórica às duas questões da metafísica como onto-teologia, resposta que consiste numa apreensão conceitual do modo através do qual o ser como presença se destina ao homem em cada época da história do Ocidente. Do mesmo modo que a história empírica dos fatos, a história do ser comporta quatro grandes épocas: antiga, medieval, moderna e contemporânea. Cada uma dessas épocas se define por um determinado regime hegemônico e normativo de presença ou manifestação do ente na totalidade: 


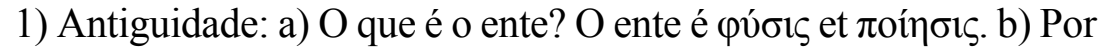

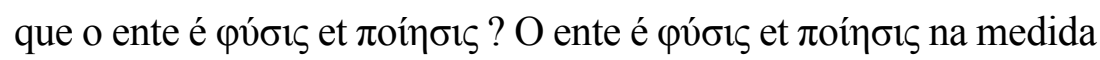

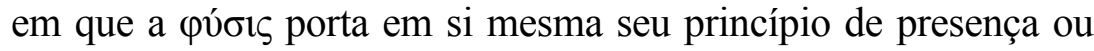

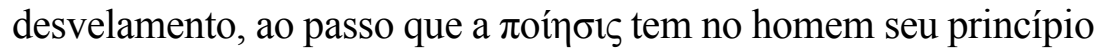
de presença e desvelamento ${ }^{6}$. Trata-se da época grega da história do ser.

2) Idade média: a) O que é o ente? $O$ ente é ens creatum. b) Por que o ente é ens creatum? Porque ele foi criado por Deus enquanto ens creator. Na segunda época da história do ser, o regime hegemônico e dominante de desvelamento ou presença do ente na totalidade não

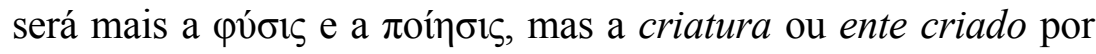
Deus concebido como criador $^{7}$. Trata-se da época latino-cristã da história do ser.

3) Modernidade: a) O que é o ente? O ente é res extensa ou objeto. b) Por que o ente é res extensa ou objeto? Porque ele é aquilo que se coloca diante (vor-sich-stellen) da res cogitans ou sujeito. Descartes é, portanto, o fundador da terceira época da história do ser em que o regime hegemônico e normativo de presença do ente na totalidade é o objeto para um sujeito ${ }^{8}$. Trata-se aqui da época moderna da história do ser.

4) Contemporaneidade: a) O que é o ente? O ente é Bestand? b) Por

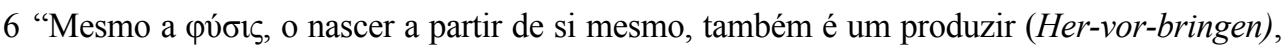

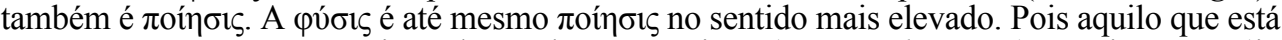

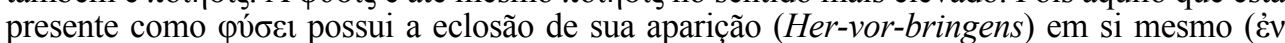
$\dot{\varepsilon} \alpha v \tau \tilde{\omega})$, por exemplo a eclosão da flor no florescimento. Por outro lado, o produto (Her-vor-gebrachte) artesanal e artístico, o prato de prata por exemplo, não possui a eclosão de sua aparição

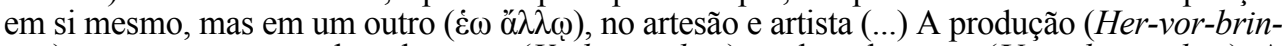
gen) opera a passagem do velamento (Verborgenheit) ao desvelamento (Unverborgenheit). A produção só acontece na medida em que aquilo que está velado (Verborgenes) torna-se desvelado (Unverborgene)" (Heidegger, 2000, p. 12-13).

7 “Aquilo que está presente (Das Anwesende) pode anunciar-se como a criatura do criador (Geschaffene des Schöpfers), que ele mesmo é aquilo que está constantemente e por toda parte presente (Anwesende) em tudo" (Heidegger, 2005, p. 39).

8 “Aquilo que está presente (Das Anwesende) pode apresentar-se (darbieten) como aquilo que, na representação humana, está posto para ela, a partir dela e diante dela. Aquilo que está presente (Das Anwesende) é portanto objetificável (Gegenständige) para a representação; enquanto percipere, a representação é o cogitare do ego cogito da conscientia, da consciência, da consciência de si do sujeito. O objeto (Gegenstand) é o objeto (Objekt) para o sujeito (Subjekt)" (Heidegger, 2005, p. 39-40).
} 
que o ente é Bestand? Por que ele é requisitado pela essência da técnica como Ge-stell. Na quarta e última época da história do ser, o objeto se transformará, portanto, em Bestand: "Lá onde o Bestand chega ao poder, o objeto (Gegenstand) enquanto característica daquilo que está presente (Anwesenden) também se desintegra" (Heidegger, 2005, p. 26) ${ }^{9}$. Trata-se da última época da história do ser. Isso posto, duas observações sobre a filosofia heideggeriana da história se fazem necessárias.

Em primeiro lugar, Heidegger pensa a passagem de uma época a outra da história do ser em termos de acontecimento (Ereignis) e não de causalidade: a "história (Geschichte) é pensada, portanto, em termos de acontecimento (ereignishaft) e não de modo causal (kausal) enquanto conexão interna de efeitos de um 'acontecer' (Geschehens)" (Heidegger, 2015, p. 48). Nesse sentido, "a história do ser (Geschichte des Seins) é em si mesma acontecimento (Ereignis) e tudo nela acontecimental (ereignishaft)" (Heidegger, 2005a, p. 173). Se o acontecimento não tem nem razão nem causa de ser, ele também não pode ser pensado em termos de necessidade e contingência, dado que tais categorias valem somente para o domínio do ente e não do ser como acontecimento: "A sequência (Folge) das épocas no destino do ser (Geschick von Sein) não é contingente (zufällig), nem passível de ser calculada como necessária (notwendig)" (Heidegger, 2007, p. 13). Em outros termos, na medida em que o acontecimento não é um ente, a história do ser e suas diferentes épocas não podem ser pensadas a partir de categorias metafísicas como essência, causalidade, necessidade, contingência, atividade, passividade, etc., visto que tais categorias são aplicáveis apenas ao ente mas nunca ao ser como acontecimento e nada. Nesse sentido, Heidegger afirma que nada acontece na história do ser, isto é, nada de entificável acontece mas o próprio ser como nada e acontecimento:

O que acontece (geschieht) na história do ser (Geschichte des Seyns)? Com essa questão nós já permanecemos presos à diferença entre aquilo que acontece e seu acontecer. Ao colocar a questão sobre 'o que' acontece (was geschieht), visamos um ente (ein Seiendes) (...) Ao colocar a questão sobre o que acontece 'na' história

9 Apesar da transformação do objeto em Bestand, Heidegger enfatiza que tal transformação "não quer dizer que a relação sujeito-objeto desapareça, pelo contrário, hoje ela atinge seu grau mais extremo de dominação (Herrschaft), tal qual ela é determinada no Ge-stell" (Heidegger, 2000, p. 55). 
do ser (Geschichte des Seyns), ou nós ainda não colocamos ou não colocamos mais a questão da 'história do ser' (Geschichte des Seyns), expressão que significa que o ser em si (Seyn in sich) é a história (Geschichte). E se conservamos, portanto, a questão na seguinte forma: o que acontece? (was geschieht?), teremos como resposta: Nada acontece (Nichts geschieht) (...) E é por isso também que a história do ser (Seynsgeschichte) é sempre desconhecida e inacessível ao esforço histórico (historischen Bemühen). Nada acontece na história do ser (Nichts geschieht in der Geschichte des Seyns). Mas o nada é o ser (das Nichts ist das Seyn). Nada acontece. $\mathrm{O}$ acontecimento acontece (Das Ereignis ereignet). (Heidegger, 2005a, p. 171-172)

Em segundo lugar, Heidegger não pensa a história do ser em termos de progresso, o que o distingue de Hegel, que postula uma espécie de necessidade lógica interna na passagem de uma época a outra da história, na passagem de uma figura a outra do espírito: consciência, consciência de si, razão, espírito, religião e saber absoluto. Jean Beaufret relata a esse respeito que "Heidegger nos alertava às vezes contra um excesso de hegelianismo; quando ele evoca, por exemplo, as diferentes filosofias em sua história, ele emprega a expressão freie Folge, 'sequência livre'. No entanto, um dia ele me disse: 'Sim, mas Folge não é bom. Não encontrei outra palavra. Folge já é hegeliano demais" (Beaufret, 1993, p. 144). Como em Heidegger o ser enquanto acontecimento não é um ente, não possuindo portanto nem razão nem causa, o momento do acontecimento de passagem de uma época a outra da história do ser comporta algo da ordem do mistério, ou seja, "algo" que não pode ser determinado nem em sua essência nem em sua razão de ser: "esse momento permanece misterioso (geheimnisvoll) como todos os momentos dessa espécie. Não são apenas os maiores pensamentos que chegam como patas de colombo, mas particularmente e antes de tudo as respectivas mudanças no (modo de) presença de tudo aquilo que está presente (Wandel des Anwesens alles Anwesenden)" (Heidegger, 2000b, p. 51-52). A concepção heideggeriana da história se distingue portanto da concepção hegeliana pelo fato de que Hegel a concebe a partir da pespectiva do progresso: "A história do mundo (Weltgeschichte) é o progresso (Fortschritt) na consciência da liberdade - progresso (Fortschritt) que temos que reconhecer em sua necessidade" (Hegel, 2015, p. 32). Ora, para Heidegger a época da técnica moderna é justamente o momento histórico em que o esquecimento do ser em nome do ente 
atinge seu ápice e acabamento: "O Ge-stell é a essência da técnica moderna. A essência do Ge-stell é o próprio ser do ente; não o ente em geral, nem desde sempre, mas no momento presente em que o esquecimento da essência do ser se realiza completamente (vollendet). $\mathrm{O}$ acontecimento dessa realização completa do esquecimento do ser (Seinsvergessenheit) determina essencialmente nossa época na medida em que o ser vigora agora na forma do Ge-stell" (Heidegger, 2005 , p. 51). Por outro lado, com bastante frequência Heidegger dá a entender que ele estima muito mais o pensamento grego, sobretudo antes de Platão e Aristóteles, que o pensamento moderno, do mesmo modo que Nietzsche, para quem "o progresso (Fortschritt) é uma mera ideia moderna, ou seja, uma ideia falsa (eine falsche Idee)" (Nietzsche, 1969, p. 169). Assim, se, por um lado, Hegel pensa a história como a história do progresso do espírito que se realiza paulatinamente, em Heidegger, a história é pensada como a história do declínio (Untergang) do Ocidente, não no sentido de Spengler mas no sentido de que o esquecimento do ser na era da técnica se expande por toda parte como nunca antes ao longo de toda a história do ser. Nesse sentido, poderíamos resumir a filosofia heideggeriana da história do seguinte modo: em seu primeiro começo (erster Anfang) com Anaximandro, Parmênides e Heráclito, o ser veio à linguagem em todo seu brilho poético e pré-metafísico (vormetaphysich) ${ }^{10}$, ou seja, ainda não capturado, despotencializado e finalmente esquecido pela metafísica. Já na Grécia antiga começa o processo histórico de degradação e esquecimento do ser com Platão e Aristóteles e a invenção da metafísica. A partir de então, a história do ser será uma sucessão de degradações e esquecimentos do ser que atravessam o cristianismo e a teologia medieval, a filosofia e ciência moderna até chegar na era da técnica com sua Machenschaft.

Isso posto, para entendermos o regime de desvelamento do ente na totalidade na era da técnica, é preciso delimitar o que Heidegger entende por Bestand e Gestell.

\section{A técnica moderna como regime de desvelamento do ente na totalidade}

Para compreendermos a questão da técnica no pensamento de Heidegger, a primeira coisa que devemos ter em mente é que ela se inscreve no âmbito da

10 "A filosofia pré-platônica (vorplatonisch) é de certo modo pré-metafísica (vor-metaphysich)" (Heidegger, 1997b, p. 383). 
história do ser como história do Ocidente. Isso significa que a metafísica como onto-teologia funda cada época da história do ser através de um regime hegemônico e normativo de desvelamento do ente na totalidade. Daí a ideia de que a determinação antropológico-instrumental da técnica é correta (richtig), mas não nos permite, contudo, apreender a essência da técnica moderna.

Em A questão da técnica (1953), Heidegger define a determinação antropológico-instrumental da técnica do seguinte modo:

Uma diz: a técnica é um meio (Mittel) para certos fins (Zwecke). A outra diz: a técnica é um fazer (Tun) do homem. Essas duas determinações da técnica são interdependentes (...) A representação corrente da técnica, segundo a qual ela é um meio e um fazer humanos, pode ser chamada, portanto, de determinação instrumental e antropológica da técnica (instrumentale und anthropologische Bestimmung der Technik). (Heidegger, 2000, p. 7-8).

Como dissemos, essa concepção é correta mas nos impede de apreender aquilo que está realmente em jogo na técnica moderna, a saber, a questão da verdade, não no sentido de adequação mas de $\dot{\alpha} \lambda \hat{\eta} \theta \varepsilon ı \alpha$, ou seja, enquanto regime hegemônico e normativo de desvelamento do ente na totalidade. Longe, portanto, de ser exclusivamente um meio ou instrumento que o homem deve dominar para alcançar certos fins, a técnica moderna é também e acima de tudo a última época da história do ser, isto é, uma modalidade de presença do ente na totalidade. Em outras palavras, "a dominação planetária da técnica não é nada mais que o acabamento (Vollendung) extremo da metafísica que começa com Platão e Aristóteles" (Heidegger, 2018, p. 297).

Se, como vimos na nota de rodapé 9, a transformação do objeto em Bestand não implica uma abolição do esquema sujeito-objeto mas sua dominação extrema, o que distingue o objeto do Bestand? Numa passagem do seminário do Thor, encontramos uma resposta para essa questão: "Hoje em dia já não há mais objetos (Gegenstände) (o ente que se mantém diante de um sujeito que o apreende através do olhar), - hoje em dia só há Bestände (o ente que se mantém pronto para ser consumido [Seiendes, das sich zum Verbrauchtwerden bereit hält])" (Heidegger, 1986, p. 367-368). Embora essa definição seja instrutiva, ela não nos permite compreender suficientemente o conceito heideggeriano de 
Bestand. Para fornecer uma definição mais precisa e completa desse conceito, temos que levar em conta o fato de que Heidegger explora o uso filosófico e econômico desse termo na língua alemã.

Uso filosófico: a palavra Bestand é um substantivo cujo verbo correspondente é bestehen, que significa, entre outras coisas, existir no sentido de vorhanden sein, ou seja, estar presente, estar disponível, existir (conceito de Vorhandenheit em Ser e tempo). Além disso, em filosofia Bestand também pode ser um sinônimo de termos como Subsistenz (subsistência), Permanenz (permanência) e Fortdauer (continuação), termos estes intimamente ligados à noção temporal do ser como presença. Por fim, o verbo bestehen enquanto sinônimo de vorhanden sein remete à ideia de estar disponível, que desempenha um papel bastante importante na noção heideggeriana de Bestand.

Uso econômico: nesse campo semântico, Bestand é um sinônimo de termos como Fonds (fundos, acervo) e Stock (estoque), daí as possíveis traduções estoque, reservatório. Bestand é também um sinônimo dos termos alemãos Vorrat, que significa provisão, reserva, estoque, e vorhandene Menge (quantidade disponível).

Tendo em vista esses dois usos do termo Bestand, poderíamos defini-lo do seguinte modo: Bestand designa o ente constantemente presente e disponível para realizar tanto uma função através de seu uso e consumo quanto para ser trocado e/ou estocado. Essa definição nos permite compreender a relação entre técnica moderna e capitalismo.

\section{Heidegger com Marx: uma leitura cruzada}

A hipótese de leitura que gostaria de defender aqui é a seguinte: uma leitura cruzada Marx-Heidegger nos permite apreender a metafísica própria à técnica moderna e, portanto, às sociedades capitalistas. Nesse sentido, lembremos dessa indicação do próprio Heidegger em Carta sobre o humanismo (1946), onde o filósofo faz alusão a "um diálogo produtivo com o marxismo (ein produktives Gespräch mit dem Marxismus)" (Heidegger, 2004a, p. 87). É verdade que no contexto em que essa frase se encontra, Heidegger se refere explicitamente ao problema da alienação (Entfremdung), ao passo que tentaremos estabelecer um diálogo produtivo com o marxismo sob outra perspectiva, a saber, mostrar que o capitalismo é ao mesmo tempo um modo de produção da vida material e uma metafisica. Em outras palavras, "teremos que fazer metafísica lá onde e enquanto fazemos economia política” (Marx, 1977, p. 125). 
Para entendermos a relação entre técnica moderna e capitalismo, é preciso levar em consideração que "no interior de uma época dominada pela mercadoria, podemos dizer que, em última instância, técnica e mercadoria são idênticas" (Badiou, 2015, p. 246). Essas afirmações se tornam mais compreensíveis se tivermos em mente as duas determinações que definem o Bestand: 1) realizar uma função através do uso e consumo. 2) ser trocado e/ou estocado. Ora, tais determinações correspondem exatamente aos conceitos de Gebrauchswerth (valor de uso) e Tauschwerth (valor de troca) da mercadoria em Marx. Ou seja, dizer que na época da técnica o ente na totalidade se desvela como Bestand significa dizer que ele se desvela de modo hegemônico e normativo como mercadoria, de modo que o capitalismo é ao mesmo tempo um modo de produção da vida material e uma metafísica enquanto regime de desvelamento do ente na totalidade: só é real, na época da técnica e do capitalismo, aquilo que está presente e se desvela como mercadoria.

O regime técno-capitalista de desvelamento do ente na totalidade implica, assim, um modo hegemônico e normativo de presença das coisas, dos homens e da natureza. As coisas possuem duas modalidades dominantes de presença: os bens de consumo e os instrumentos utilizados para produzi-los, ambos se desvelando como Bestand, ou seja, entes constantemente presentes e disponíveis para realizar uma função através de seu uso e consumo, para serem trocados e/ou estocados. Por outro lado, os próprios homens também possuem um modo dominante de presença, a saber, enquanto trabalhador que produz bens de consumo utilizando instrumentos. Enquanto trabalhador, o homem também é um ente que deve estar constantemente presente e disponível para realizar sua função na cadeia produtiva através do uso e consumo de sua força de trabalho (Arbeitskraft), esta sendo uma mercadoria que pode ser comprada, isto é, trocada por um salário: "Na medida em que ele é comprado e vendido, o trabalho é uma mercadoria (Arbeit ist eine Ware) como qualquer outra mercadoria, tendo portanto um valor de troca" (Marx, 1977, p. 88). Por fim, a natureza possui a seguinte modalidade hegemônica e normativa de presença: o Bestand no sentido de reservatório de energia e matéria prima. Nesse sentido, a natureza como Bestand também se desvela como um ente constantemente presente e disponível para realizar a função de fornecer aos homens matéria prima e energia para a produção incessante de mercadorias que serão trocadas e/ou estocadas.

Isso dito, uma questão se impõe: se, ao longo de toda a história da civilização, a natureza, os homens e coisas realizaram essa função no interior da produção da vida material do homem, por que somente na época da técnica existe um regime de desvelamento do ente na totalidade como Bestand? A resposta é 
a seguinte: porque na era da técnica, tal regime se torna hegemônico e normativo, ou seja, só é real aquilo que está constantemente presente e disponível para realizar uma função através do uso e consumo, da troca e/ou estoque. Nesse sentido, se a natureza se desvelava como púoıৎ na antiguidade, como criatura divina na idade média e como objeto na modernidade, na época da técnica moderna "a natureza [se desvela] como o principal reservatório (Hauptspeicher) de estoque de energia (Energiebestandes)" (Heidegger, 2000, p. 22) e matéria prima, o que implica, como se sabe, uma dominação, exploração e destruição da natureza sem precedentes na história. Para Heidegger, a diferença decisiva entre a técnica moderna e os outros regimes de desvelamento do ente na totalidade reside, portanto, no fato de que a técnica armazena e estoca a energia da natureza, violência que nunca havia existido anteriormente na história do ser. Numa passagem de $A$ questão da técnica, o filósofo alemão ilustra o próprio do regime técnico de desvelamento da natureza a partir do exemplo de um moinho de vento: "O modo de desencobrimento (Entbergen) que rege a técnica moderna é uma extração desafiadora (Herausfordern) através da qual a natureza recebe o ultimato de fornecer uma energia que possa ser extraída e estocada enquanto tal. Isso não vale também para o moinho de vento? Não: suas hélices giram de fato com o vento e estão entregues diretamente a seu sopro. Mas o moinho de vento não explora a energia eólica para armazená-la (speichern)" (Heidegger, 2000, p. 15).

Nós podemos resumir o próprio do regime técnico de desvelamento do ente na totalidade do seguinte modo: a natureza se desvela como reservatório de energia e matéria prima que podem ser não somente consumidos mas acima de tudo estocados; os homens se desvelam de modo hegemônico e normativo como trabalhador que cumpre sua função na cadeia produtiva através do uso e consumo da sua força de trabalho que é trocada por um salário; a aparelhagem técno-científica com suas máquinas e instrumentos altamente sofisticados se desvelam como meio de transformação da natureza a fim de extrair, estocar e utilizar sua energia e matéria prima numa escala jamais vista antes, transformação da natureza que visa produzir incessantemente coisas que se desvelam como mercadorias em nossas sociedades de consumo, sociedades em que as condições de vida do homem se desvela em todas as suas esferas da existência - mundo do trabalho, economia, política, arte, educação, etc. - como massificação, reificação, alienação, exploração, homogeneização e dominação crescentes do homem sobre a natureza, do homem sobre si mesmo e sobre os outros homens no interior de nossas formas de vida e práticas sociais.

No pensamento de Heidegger, a essência da técnica consiste naquilo que ele 
chama de Ge-stell, termo de difícil tradução. Em seu uso ordinário, esse termo significa estante e mais raramente suporte e ossatura. No entanto, Heidegger nos alerta para o fato de que o uso que ele faz desse termo é bastante peculiar em relação ao seu uso ordinário: "Nós nos arriscamos a utilizar essa palavra [das Ge-stell] num sentido até aqui totalmente inabitual" (Heidegger, 2000, p. 20). Toda a dificuldade de tradução consiste no fato de que Heidegger joga com o prefixo Ge e a raíz stell. Em alemão, quando o prefixo Ge é utilizado para compor uma palavra com um termo que vem a seguir, ele significa reunião daquilo que se segue ao prefixo. Por exemplo: a palavra Berg significa montanha, o termo Ge-birge designando a reunião de montanhas, o conjunto de montanhas ou cordilheira. Isso posto, Heidegger utiliza o termo Ge-stell para designar a reunião ou conjunto de diferentes formas de stellen: vor-stelen, be-stellen, her-stellen, er-stellen, aus-stellen, etc.: "Ge-stell é a reunião (Versammlung), o conjunto de todos os modos de Stellen que se impõem ao ser humano na medida em que ele ek-siste hoje" (Heidegger, 1986, p. 388). No texto Para que poetas? (1946), Heidegger fala de diferentes forma de stellen que nos ajuda a entender seu conceito de Ge-stell: "Temos que pensar esse pro-duzir (Her-stellen) em sua essência vasta e múltipla. O homem encomenda (bestellen) a natureza lá onde ela não basta à sua representação. $\mathrm{O}$ homem produz (stellt her) coisas novas lá onde elas estão em falta. O homem reorganiza (stellt um) as coisas lá onde elas causam perturbação. O homem as dissimula (verstellt) lá onde elas o desviam de seus objetivos. O homem expõe (stellt aus) as coisas lá onde ele as promove tendo em vista a venda e o uso. O homem expõe (stellt aus) lá onde ele exibe suas próprias performances e realizações (Leisten) e contrata para a sua indústria. Através dessas múltiplas formas de produção, o mundo se torna aquilo que está aí diante de nós, sendo levado a permanecer assim" (Heidegger, 1977, p. 288). Essa passagem nos mostra de modo exemplar que toda a dificuldade da tradução do termo Ge-stell reside no fato de que é impossível conservar a ideia de reunião que remete a todas essas diferentes formas de stellen, que possuem um significado decisivo no interior da técnica moderna. Quando Heidegger postula, portanto, que a essência da técnica é o Ge-stell, ele visa designar o regime técnico de desvelamento do ente na totalidade como Bestand enquanto reunião de uma série de significados de termos construídos a partir do termo stellen. Nesse sentido, a totalidade do ente se desvela como Bestand na medida em que a essência da técnica é o Ge-stell enquanto reunião de diversas formas de stellen. No entanto, se, por um lado, Heidegger faz um uso totalmente peculiar do termo alemão Ge-stell, por outro lado, os significados correntes como estante, suporte e ossatura são de certo modo conservados, visto que eles remetem à imagem de algo que estrutura e fornece suporte e sustentação. 


\section{Conclusão}

Como se sabe, Marx começa o primeiro volume do Capital (1867) com uma análise da mercadoria e suas duas formas de valor. Ele define o valor de uso do seguinte modo: "A mercadoria é em primeiro lugar um objeto exterior (äußerer Gegenstand), uma coisa (Ding) que através de suas qualidades satisfaz necessidades humanas de qualquer espécie (...) A utilidade de uma coisa faz dela um valor de uso (Gebrauchswerth)" (Marx, 1991, p. 37-38). Já o valor de troca é definido assim: "O valor de troca (Tauschwerth) aparece inicialmente como relação quantitativa, a proporção em que valores de uso de uma espécie são trocados por valores de uso de uma outra espécie, uma relação que varia constantemente de acordo com o tempo e o lugar” (Marx, 1991, p. 38-39).

Se o valor de uso diz respeito ao aspecto qualitativo e material da mercadoria, cuja função é satisfazer as necessidades humanas através de seu uso e consumo, por outro lado, o valor de troca designa o aspecto quantitativo que torna possível sua circulação no mercado. Segundo Marx, a condição de possibilidade do valor de troca não é nada mais, nada menos que a identidade ou igualdade (Gleiche) que existe entre todas as mercadorias, isto é, um denominador comum que torna possível o estabelecimento da proporção e equivalência das mercadorias entre elas para que possam circular no mercado: "Uma certa mercadoria, um quarter de trigo por exemplo, é trocado por uma quantidade $x$ de graxa de sapato ou $y$ de seda ou $z$ de ouro, etc., em suma, por outras mercadorias segundo as proporções mais diferentes. Ao invés de um único valor de troca, o trigo tem, portanto, múltiplos valores de troca. Mas como uma quantidade $x$ de graxa de sapato, assim como $y$ de seda ou $z$ de ouro, etc., são o valor de troca de um quarter de trigo, logo é preciso que as quantidades $x$ de graxa de sapato, $y$ de seda, $z$ de ouro, etc., sejam valores de troca substituíveis (ersetzbare) uns pelos outros, ou ainda de grandeza igual. Primeira consequência: os valores de troca reconhecidos da mesma mercadoria expressam algo de idêntico (Gleiches)" (Marx, 1991, p. 39).

Em outras palavras, mercadorias diferentes (graxa, seda, ouro, trigo, etc.) devem ter uma identidade, algo em comum para que possamos compará-las e estabelecer relações de equivalência. A relação entre identidade e diferença no cerne do valor de troca é exemplificado por Marx através da relação entre o trigo e o ferro: "Consideremos ainda duas mercadorias, o trigo e o ferro por exemplo. Qualquer que seja sua relação de troca, ela sempre é apresentável através de uma equação (Gleichung) em que uma quantidade dada de trigo é igualada (gleichgesetzt) a uma quantidade qualquer de ferro, por exemplo, 1 quarter de trigo $=1$ quintal de ferro. $\mathrm{O}$ que diz essa equação? Que existe algo de comum 
(Gemeinsames) e de mesma (derselbe) grandeza em duas coisas diferentes (zwei verschiedenen Dingen), em 1 quarter de trigo assim como em 1 quintal de ferro. As duas coisas são portanto idênticas (gleich) a uma terceira, que em si e para si não é nem uma, nem outra. Cada uma das duas, na medida em que é valor de troca, deve portanto ser redutível a essa terceira" (Marx, 1999, p. 39).

O que mais chama atenção nessa passagem são os termos que Marx utiliza para explicar a relação entre identidade e diferença no valor de uso: Gleichung, que significa equação e deriva da mesma raíz que gleich, adjetivo que pode ser traduzida por idêntico ou igual em função do contexto; Gemeinsames, que significa aquilo que é comum a vários entes distintos, não sendo nada mais do que a essência ou o conceito no sentido de uma representação universal enquanto síntese do múltiplo da experiência na unidade ou identidade do conceito; derselbe, que significa o mesmo, um dos atributos fundamentais da noção de identidade junto com a unidade. Todos esses termos nos mostram que, sem a estrutura metafísica da identidade e diferença, não existiria valor de troca das mercadorias, o que nos indica que determinações metafísicas nunca são puramente metafísicas, pois estão em relação com determinações do campo social.

Para Marx, a produção da identidade das mercadorias depende de um duplo processo de abstração e apagamento da diferença: primeiro, a abstração das diferentes qualidades sensíveis do valor de uso da mercadoria, segundo, a abstração dos diferentes trabalhos e profissões concretos através dos quais as mercadorias são produzidas:

Se abstrairmos o corpo das mercadorias do valor de uso, só lhes resta uma única propriedade: a de serem produtos do trabalho. No entanto, mesmo o produto do trabalho já se transformou em nossas mãos. Ao abstrair o valor de uso, nós também abstraímos de uma só vez os componentes corporais e formas que fazem da mercadoria um valor de uso. Ela deixa de ser mesa, casa, fio ou qualquer outra coisa útil. Todas essas propriedades sensiveis são apagadas. Ela deixa igualmente de ser o produto do trabalho do marceneiro, do pedreiro, do tecelão, em suma, de qualquer trabalho produtivo determinado. Junto com as propriedades úteis dos produtos do trabalho desaparecem as propriedades dos trabalhos presentes nesses produtos, e com isso as diferentes formas concretas desses trabalhos (verschiednen konkreten Formen dieser 
Arbeiten), eles não se distinguem mais (unterscheiden sich nicht länger), eles se confundem todos uns com os outros, se reduzem ao trabalho humano idêntico (gleiche menschliche Arbeit), ao trabalho humano abstrato (abstrakt). (Marx, 1991, p. 40).

Essa passagem é decisiva para compreendermos a dimensão metafísica do valor de troca: para que as mercadorias possam ser trocadas, é preciso abstrair previamente as diferenças sensíveis da mercadoria (valor de uso), assim como os diferentes trabalhos concretos que a produzem, daí o conceito marxista de abstrakte Arbeit (trabalho abstrato), que não é nada mais do que o trabalho humano idêntico (gleiche menschliche Arbeit). O resultado dessas duas operações de abstração é duplo: por um lado, o dinheiro torna-se o equivalente geral de todas as mercadorias, por outro, o dinheiro enquanto equivalente geral apaga todas as diferenças concretas entre as mercadorias: "No dinheiro, toda diferença (alle Verschiedenheit) das mercadorias é apagada (ausgelöscht), isso porque o dinheiro é justamente a forma equivalente comum (gemeinsame Aequivalentform) de todas as mercadorias" (Marx, 2008, p. 46).

Em outras palavras, a moeda é a essência de todas as mercadorias, de modo que, se na Idade média o Deus criador estava presente em todos os entes concebidos como criaturas, se nos tempos modernos o sujeito estava presente em todos os entes concebidos como objeto, na época do capitalismo a moeda estará presente em todos os entes concebidos como mercadoria, o que nos mostra a dimensão metafísica do capitalismo. Nesse sentido, Badiou diz que o capitalismo "é o reino da mercadoria, do equivalente geral, da moeda como aquilo que faz tudo equivaler. Nós também temos um conceito marxista de indiferença, todas as coisas tornam-se indiferentes porque estão sob a lei do equivalente geral, a moeda" (Badiou, 2015, p. 61).

Um último elemento nos permite aprofundar a dimensão metafísica do capitalismo: em suas análises da mercadoria, Marx nos mostra que ela é um ente fundamentalmente metafísico, isto é, sensível-inteligível:

(...) assim que ela [mesa] entre em cena como mercadoria, ela se transforma numa coisa sensível-inteligível (sinnlich übersinnliches Ding). (Marx, 1991, p. 70). 
A mercadoria é uma coisa sensível-inteligível na medida em que o valor de uso diz respeito às qualidades materiais da mercadoria, ao passo que o valor de troca refere-se ao inteligível enquanto tempo médio de trabalho socialmente necessário para produzir as mercadorias. Isso significa que quando vemos uma mercadoria qualquer, percebemos imediatamente apenas suas qualidades sensíveis, o conjunto de seu processo de produção nunca sendo dado numa percepção sensível da mercadoria. O valor de uso designa, portanto, o mundo sensível das diferenças, ao passo que o valor de troca refere-se ao mundo inteligível da identidade, o que faz com que determinações metafísicas estejam no coração da mercadoria como coisa sensível-inteligível.

Nós podemos concluir, portanto, que no interior do capitalismo o princípio de identidade foi levado ao extremo de sua dominação mundial: "A identidade (Identität) é a forma originária (Urform) da ideologia (Ideologie)" (Adorno, 1996, p. 151). Dito de outro modo, no interior do capitalismo reina a identidade abstrata da moeda que elimina a diferença concreta das mercadorias, trabalhos e profissões. Nesse sentido, a diferença entre as mercadorias é uma diferença subordinada à identidade, ou seja, diferença daquilo que pode ser substituído e trocado. Daí porque, de acordo com Marx, "enquanto valor de troca, toda mercadoria é idêntica (ou comparável) [vergleichbar] às outras [mercadorias]" (Marx, 1983, p. 85).

Esse cruzamento entre Marx e Heidegger nos permite compreender mais claramente em que sentido o capitalismo não é exclusivamente um modo de produção da vida material, mas também uma metafísica, isso em quatro sentidos: 1) Enquanto regime hegemônico e normativo de desvelamento ou presença do ente na totalidade como mercadoria. 2) Na medida em que o dinheiro é, enquanto equivalente geral, aquilo que está presente em toda mercadoria, assim como Deus estava presente em toda criatura e o sujeito em todo objeto. 3) $\mathrm{Na}$ medida em que a mercadoria é um ente sensível-inteligível. 4) Na medida em que a categoria metafísica de identidade está no cerne mesmo da noção de valor de troca. Em suma, o capitalismo não é somente um modo de produção mas também uma onto-teologia, isto é, uma resposta histórico-metafísica às questões: 1) O que é o ente? O ente é mercadoria. 2) Por que o ente é mercadoria? Porque o dinheiro enquanto equivalente geral é seu fundamento ontológico.

A técnica moderna como metafísica do modo de produção capitalista produziu e produz constantemente a massificação, reificação, alienação, exploração, destruição, homogeneização e dominação crescentes do homem sobre a natureza, do homem sobre si mesmo e do homem sobre os outros homens. Daí porque 
"lá onde o Ge-stell domina, mora o perigo (Gefahr) no sentido supremo. 'Mas lá onde mora o perigo, cresce também a salvação"” (Heidegger, 2000, p. 29). É justamente nesse ponto que aparece o grande limite de Heidegger que nos conduz diretamente ao pensamento de Marx e de Deleuze e Guattari: nossa salvação diante dos perigos do capitalismo não é a espera de novos deuses mas uma revolução sócio-econômica-desejante.

Recebido em: 14.05.2019| Aprovado em: 13.06.2019 $\{$ Referência Bibliográfica

ADORNO, T. W. Negative Dialektik, In: GS 6, Frankfurt: Suhrkamp, 1996 (5a edição).

ARISTÓTELES. Metaphysica, ed. I. Bekker, Berlim: Reimer, 1831.

BADIOU, A. Heidegger, Paris: Fayard, 2015.

BEAUFRET, J. In: TOWARNICKI, F. À la rencontre de Heidegger, Paris: Gallimard, 1993.

HEGEL, G. W. F. Vorlesungen über die Philosophie der Geschichte, Werke 12, Frankfurt: Suhrkamp, 2015 (2a edição).

HEIDEGGER, M. Anmerkungen I-V, GA 97, Frankfurt: Klostermann, 2015.

.Besinnung, GA 66, Frankfurt: Klostermann, 1997b.

.Bremer und Freiburger Vorträge, GA 79,
Frankfurt: Klostermann, 2005 (2a edição).

.Brief über den »Humanismus«, In: Wegmarken, GA 9, Frankfurt: Klostermann, 2004a (2a edição).

.Der deutsche Idealismus (Fichte, Schelling, Hegel) und die philosophische Problemlage der Gegenwart, GA 28, Frankfurt: Klostermann, 1997a.

.Der Satz vom Grund, GA 10, Frankfurt: Klostermann, 1997 (2a edição).

"Die Frage nach der Technik", In: Vorträge und Aufsätze, GA 7, Frankfurt: Klostermann, 2000 (2a edição).

.Die Metaphysik des deutschen Idealismus, GA 49, Frankfurt: Klostermann, 1991.

Einführung in die Metaphysik, GA 40, Frankfurt: Klostermann, 1983 (5ª edição). 
.Hegel, GA 68, Frankfurt: Klostermann,

1993.

.Hegels Phänomenologie des Geistes, GA

32, Frankfurt: Klostermann, 1997 (3a edição).

"Platons Lehre von der Wahrheit", In: Wegmarken, GA 9, Frankfurt: Klostermann, 2004 (2a edição).

.Schelling: Vom Wesen der menschlichen Freiheit (1809), GA 42, Frankfurt: Klostermann, 1988 (2a edição).

.Seminare, GA 15, Frankfurt: Klostermann, 1986.

.Über den Anfang, GA 70, Frankfurt: Klostermann, 2005a.

. “Überwindung der Metaphysik”, In: Vorträge und Aufsätze, GA 7, Frankfurt: Klostermann, 2000a (2a edição).

."Wissenschaft und Besinnung", In: Vorträge und Aufsätze, GA 7, Frankfurt: Klostermann, 2000b (2a edição).

“Wozu Dichter?", In: Holzwege, GA 5, Frankfurt: Klostermann, 1977.

.Zeit und Sein", In: Zur Sache des Denkens, GA 14, Frankfurt: Klostermann, 2007 (2a edição)

.Zu eigenen Veröffentlichungen, GA 82, Frankfurt: Klostermann, 2018.

.Zu Ernst Jünger, GA 90, Frankfurt: Klostermann, 2004b.

MARX, K. Das Elend der Philosophie, In: MEW 4, Berlim: Dietz, 1977.

.Das Kapital I, MEGA 10, Berlim: Dietz, 1991.

.Das Kapital II, MEGA 13, Berlim:
Akademie, 2008.

.Einleitung [zu den „Grundrissen der Kritik der politischen Ökonomie], In: MEW 42, Berlim: Dietz, 1983.

NIETZSCHE, F. Der Antichrist, in KGW VI/3, Berlim: de Gruyter, 1969. 